\title{
Desigualdad Social y Trabajo Social
}

\section{Ruth Lizana Ibaceta*}

\section{RESUMEN}

El presente artículo referido a desigualdad social, busca reconocer esta realidad como una preocupación del Trabajo Social. Por ello se presentan antecedentes de la realidad social latinoamericana, donde la desigualdad social, si bien es permanente en nuestra historia, hoy se constituye en un imperativo ético a abordar. Para ello se propone resituar el valor de la justicia social como convocante de la actuación profesional de trabajadores sociales.

Palabras clave: Desigualad social; pobreza; exclusión, ética.

\section{ABSTRACT}

This article referred to social inequality, looking recognize this as a concern of Social Work. Therefore presents background to the social reality of Latin America, where social inequality, while standing in our history, today is an ethical imperative to address. It proposes resituate the value of social justice as convener of the performance of social workers.

Key words: Social Inequality, poverty, exclusion, ethics.

* Trabajadora Social. Académica del Departamento de Trabajo Social de la Universidad Católica Silva Henríquez. E-mail:rlizana@UCSH.cl 


\section{Antecedentes}

I a realidad de la desigualdad social ha sido siempre una preocupación para el Trabajo Social, podemos encontrar ya en los Lrígenes de la profesión un marcado interés por abordar dichas situaciones. La llamada cuestión social, espacio en que se expresa de manera fragrante la desigualdad social (Netto 2006), ha sido desde siempre objeto constitutivo del quehacer del Trabajo Social.

A decir de Juan Pablo Netto (2006), el Trabajo Social latinoamericano está comprometido con la igualdad social, entendiéndola como única condición capaz de propiciar a todos y a cada uno de los individuos sociales las condiciones para su libre desarrollo. Las expresiones de la desigualdad social son una realidad que los trabajadores sociales conocemos muy de cerca, las distancias o diferencias bajo las cuales se desarrolla la vida de las personas se constituye en el espacio del quehacer del Trabajo Social.

Bank (1997 citando a Spicker;1998) señala que la igualdad significa "la transformación de las desigualdades" donde, para el ejercicio profesional de los trabajadores sociales, se puede interpretar a lo menos de tres maneras: trato igual, es decir prevenir la desigualdad de acceso a los servicios, incluyendo el trato sin prejuicios o favores; igualdad de oportunidades, entendida como la eliminación de la desigualdad en la competencia con los demás, otorgando a las personas los medios para alcanzar fines socialmente deseables y, en tercer lugar, igualdad de resultados, en la cual las desigualdades se eliminan del todo.

Hablar de América Latina, hoy es hablar de y desde la desigualdad. Ziccardi (2001) nos señala que la desigualdad social ha sido componente constitutivo de la sociedad y la ciudad latinoamericana, pero la misma se ha incrementado tanto, que se estima que en la actualidad es mayor a la imperante en los años ' 60 o principio de los'70.

En nuestros países, señala la autora, persisten grandes desigualdades en el acceso a bienes y servicios, también es posible reconocer desigualdad en los ingresos derivados de las marcadas diferencias en el nivel de educación y a la segmentación del mundo del trabajo, desigualdades en el acceso a la tierra. De modo que el atributo más característico de la desigualdad de los ingresos en América Latina es la concentración inusualmente alta de éste en el extremo superior 
de la escala. (La cifra es comparable sólo con algunos países de África y los estados de la ex Unión Soviética). A modo de comparación, el 10\% más rico de Estados Unidos recibe el 31\% del ingreso total y en Italia, éste recibe el $27 \%$. Incluso en los países más equitativos de América Latina (Costa Rica y Uruguay), el nivel de desigualdad en los ingresos es significativamente mayor.

La inequidad en el consumo -cuando se puede medir en forma adecuada- también parece ser más alta en los países latinoamericanos, aunque, aparentemente, las diferencias con otras regiones no son tan acentuadas como en el caso de la desigualdad en los ingresos.

De acuerdo con las encuestas domiciliarias, el 10\% más rico de los individuos recibe entre el $40 \%$ y el $47 \%$ del ingreso total en la mayor parte de las sociedades latinoamericanas, mientras que el 20\% más pobre, sólo recibe entre el 2\% y el 4\% (Banco Mundial 2003).

La desigualdad en nuestras sociedades es la más grande del mundo. En Chile el 20\% más rico se apropia de más del $62.2 \%$ del ingreso nacional y el 20\% más pobre sólo consigue el 3.3\% del mismo (Terram 2004).

Por lo general, las desigualdades en educación, salud, el suministro de agua, saneamiento, electricidad y la telefonía también son importantes y están correlacionadas con las diferencias en los ingresos (Banco Mundial 2003).

A modo de ejemplo, podemos señalar que, en la región, las diferencias en el promedio de años de educación entre los quintiles de ingreso superior e inferior, fluctúan entre 5 y 9 años para las personas entre 31 y 40 años y entre 51 y 60 (Banco Mundial 2003).

"En el caso chileno, un niño que ingresa a un colegio público o a uno privado, obtiene una calidad de educación muy diferente. Para examinar la diferencia de la calidad de la educación, se puede comparar los resultados de la prueba SIMCE ( $4^{\circ}$ Año Básico) en Castellano y Matemáticas para colegios municipales (57\% de la matrícula) y colegios particulares ( $8 \%$ de la matrícula). A nivel de niños de entre 9 y 10 años, aquellos que van a colegios particulares tienen (en 1996) un rendimiento en castellano y matemáticas que es un 26,2\% superior al de los niños que van a colegios municipales. Este diferencial es lo suficientemente significativo para discriminar entre cuáles niños van 
a tener una mayor probabilidad de éxito para poder eventualmente ingresar a la universidad" (Meller 1997)

Señala el informe del Banco Mundial (2003) que las encuestas estándar no proporcionan datos comparables sobre la desigualdad en el ejercicio del poder o influencia dentro de una sociedad, pero su importancia y relación con la riqueza está avalada por abundante información política, histórica y sociológica.

Con respecto a los servicios y la inversión en capital humano, la tendencia general de la década pasada fue más positiva, informa el Banco Mundial. La mayor parte de la región experimentó al menos cierta igualdad en cuanto a acceso a servicios y nivel de educación básica. Sin embargo, en un área clave, la de acceso a la educación superior, el patrón predominante fue la profundización de las diferencias entre los ricos y los pobres, puesto que la asistencia aumentó con mayor rapidez entre los miembros de las familias del extremo superior de la distribución.

El profesor James K. Galbraith, director del "Proyecto Desigualdad" de la Universidad de Texas, señala que "el elemento global de la desigualdad dentro de los países se mantuvo estable desde 1963 hasta 1971, descendió hasta 1979, para luego aumentar de manera abrupta y constante en los siguientes 20 años" (Social Watch 2005:16)

Ziccardi (2001) citando a Fitoussi y Rosavallon (1997) señala que estamos en una "nueva era de las desigualdades" ya que "por un lado persisten las llamadas desigualdades tradicionales o estructurales producto de la jerarquía de ingresos entre categorías sociales (obreros, ejecutivos, empleados, etc.) las cuales se ampliaron y se modificaron en relación con la percepción que tiene la sociedad de las mismas. Por el otro, aparecen nuevas desigualdades "que proceden de la recalificación”, es decir, son desigualdades "intracategoriales”.

Es así como los autores citados por Ziccardi, proponen un "repertorio de desigualdades que se fundan en: i) la desaparición del modelo clásico de trabajo asalariado, bajo el efecto de la desocupación masiva que no afecta a todos los individuos al mismo tiempo y no depende sólo de las capacidades individuales, sino de la forma como se relacionan estos con la coyuntura; ii) las mujeres que se han integrado a la economía pero aceptando numerosas diferencias con los hombres en materia salarial, de precarización del trabajo, y entre las 
que se advierten mayores índices de desempleo; iii) las desigualdades sociales; iv) las prestaciones sociales que están condicionadas a los recursos del beneficiario potencial; v) las facilidades u obstáculos para acceder al sistema financiero; vi) la situación diferencial que se advierte en la vida cotidiana frente a la salud, la vivienda, a los equipamientos públicos, al transporte."(Ziccardi 2001: 100)

\section{Desigualdad y pobreza}

Esta desigualdad tiene su expresión en la pobreza, la que ha sido definida desde diversas perspectivas ${ }^{1}$ :

"Pobreza existe cuando una o más personas están o caen bajo un cierto nivel de bienestar económico considerando como un mínimo razonable, ya sea en términos absolutos o por estándares de una sociedad específica (Lipton E Ravallion, 1995)"

"Pobreza es entendida como la inhabilidad para obtener un estándar de vida mínimo (Banco Mundial, 1990)."

"Pobreza se refiere a una falta de (...) activos e ingresos. Incluye -pero es más que- el hecho de ser pobre por ingresos (Chambers 1995 en Mideplan 2002)".

Por su parte, el PNUD² es referido en el documento anteriormente citado, incorporando el concepto de desarrollo humano, como una propuesta de transformación de las situaciones de pobreza "Si desarrollo humano es acerca de aumentar alternativas de pobreza, significa que las oportunidades y alternativas más básicas para el desarrollo humano son denegadas - tener una vida larga, saludable y creativa y disfrutar de un estándar de vida decente, libertad, autoestima y respeto por los otros"(Mideplan 2002: 5)

La pobreza, bajo este enfoque, es definida como "la carencia de oportunidades para desarrollar capacidades". Podríamos señalar, entonces, que la pobreza no solamente debe verse como falta de ingresos, sino como una privación para el desarrollo de capacidades básicas.

Estas definiciones han sido tomadas de "Documento de Trabajo de Mideplan: Síntesis de los principales enfoques, métodos y estrategias para la superación de la pobreza. 2002

2 PNUD. Programa de la Naciones Unidas para el Desarrollo. 
En este sentido, "la pobreza incluiría la falta de las oportunidades más básicas para el desarrollo humano que, a su vez, permitirían vivir una vida larga, saludable y creativa, y disfrutar un nivel de vida decente, con libertad, dignidad, autoestima y respeto(Olavarría 2001).

Según el Programa de Acción de la Cumbre Social la pobreza tiene diversas manifestaciones: falta de ingresos y de recursos productivos suficientes para garantizar medios de vida sostenible, hambre y mal nutrición, mala salud, falta de acceso o acceso limitado a la educación y a otros servicios básicos, aumento de la morbilidad y la mortalidad a causa de enfermedades, carencia de vivienda o vivienda inadecuada, entornos que no ofrecen condiciones de seguridad, y discriminación y exclusiones sociales.

Al ampliarse el concepto de pobreza, también surgen nuevas formas de medirla que ha trabajado principalmente el PNUD, entre ellas: el IDH (índice de desarrollo humano); IPH (índice de pobreza humana); IDG (índice de desarrollo relativo al género); IPG (índice de potenciación de género), que buscan responder a miradas más complejas de la pobreza.

Señala el Informe 2005 de Social Watch, que el mundo tiene los medios para erradicar la pobreza. Esto es posible y debe hacerse. El hambre, la desnutrición y la condena a vivir en la pobreza son una afrenta a la humanidad y una negación de los derechos humanos básicos; señala el mismo informe que los actuales indicadores de pobreza invisibilizan a las mujeres, pero podríamos decir que también invisibilizan a los pueblos originarios, a las personas que tienen necesidades especiales, por ejemplo: niños, discapacitados y adultos mayores.

\section{Desigualdad y exclusión social}

Decíamos anteriormente que la desigualdad tiene su expresión en la pobreza, del mismo modo que se manifiesta como exclusión social. Fenómeno este último que deja a vastos sectores de la población de América Latina sin poder alcanzar una calidad de vida digna. La Organización Internacional del Trabajo define exclusión de la siguiente manera: "A grandes rasgos se refiere a un debilitamiento o quiebre de los lazos (vínculos) que unen al individuo con la sociedad, aque- 
llos que le hacen pertenecer al sistema social y tener identidad en relación a éste" (Barros 1996:1).

A partir de ahí podemos establecer una diferenciación social entre los que están dentro (incluidos) y los que están fuera (excluidos).

Este quiebre refiere según Xiberras (En Barros 1996) a tres tipos de vínculos: sociales, comunitarios e individuales. La exclusión es una trayectoria de sus repetidas y crecientes rupturas en ese sentido.

Los lazos que unen a las personas con su entorno social son todos aquellos que les involucran en la dinámica social y colectiva, es decir, que les implica o conduce a relacionarse con otros individuos de un modo coordinado y acorde a los patrones conductuales que son socialmente aceptados."El concepto de exclusión social adquiere una perspectiva relacional. Los que están "fuera" no sufren el problema de un atributo sino el de una posición en una determinada relación con los que están "dentro". Por lo tanto, el cambio que se requiere es un cambio en la relación, en el funcionamiento; lo que involucra tanto a los que están excluidos como a los incluidos también" (Barros 1996: 2).

Por otra parte, en la medida que ha ido progresando el concepto de exclusión social pasó a incluir no solamente aspectos materiales sino también simbólicos. Expresa no solo privaciones materiales (problemas de sobrevivencia) sino también comenzó a indicar la incapacidad de la sociedad para incluir un número cada vez mayor de individuos y grupos sociales. De ahí que el concepto de exclusión, empezó a dar cuenta de las rupturas existentes en el interior del tejido social y dentro de los valores comunitarios. Esta pasó a ser un síntoma de desintegración y una amenaza contra la cohesión social.

De ese modo, la exclusión se concibió como "un proceso gradual de quebrantamiento de vínculos sociales y simbólicos con significación económica, institucional e individual que normalmente unen al individuo con la sociedad. La exclusión acarrea a la persona el riesgo de quedar privada del intercambio material y simbólico con la sociedad en su conjunto" (Silver 1994 en Barros 1996:54).

Podemos segmentar el concepto de exclusión, analíticamente, en tres dimensiones básicas: dimensión económica (incapacidad de 
acceder a los medios para participar en los intercambios productivos); dimensión política (desigualdad o carencia de derechos civiles, políticos y sociales) y dimensión sociocultural (dificultad o impedimento de acceso a la dinámica general de la sociedad).

En América Latina, la exclusión social no es un fenómeno reciente, sino que ha sido una situación vivida por grandes mayorías. Esta situación pudo haberse ampliado a partir de la aplicación de políticas neoliberales y en particular en América Latina alude a un fenómeno producto de la interacción de una pluralidad de procesos (o factores) elementales que afectan a los individuos y a los grupos humanos, impidiéndoles acceder a un nivel de calidad de vida decente, y/o participar plenamente, según sus propias capacidades en los procesos de desarrollo (Ziccardi, 2001).

\section{El Trabajo Social frente a la desigualdad}

La preocupación del Trabajo Social y de las y los trabajadores sociales por las condiciones de desigualdad, pobreza y exclusión social, en que viven numerosos sectores de América Latina, se debe sin lugar a dudas a las implicancias éticas, económicas, sociales y políticas que estos fenómenos entrañan.

Para el PNUD³, la pobreza es una brutal negación de los derechos humanos y ello elimina la errónea noción de que el bienestar social, la educación, la salud y el empleo son favores o actos de caridad de los gobiernos y de los organismos internacionales, en beneficio de los pobres. La pobreza niega libertades, capacidades, derechos y oportunidades a las personas para tener una vida larga, creativa y sana, adquirir conocimientos, tener libertad, dignidad y respeto por sí mismas. La pobreza, parafraseando a Daniela Sánchez (1980), no es sólo una deteriorada calidad de vida sino además una frustrada experiencia humana.

Una sociedad sumergida en el desasosiego, la desesperanza y la inseguridad, es una sociedad que compromete seriamente la estabilidad democrática, señala el PNUD. La democracia no puede afianzarse mientras grandes sectores son social, cultural, económica y políticamente excluidos. Si la institucionalidad democrática no

\footnotetext{
Para más detalles ver: www.pnud.org.ve/temas/pobreza.asp
} 
tiene como pilar el bienestar social, se desvanecen las condiciones para alcanzar un desarrollo económico sostenible.

Los niveles de desigualdad que predominan en América Latina tienen un alto costo para el bienestar. De acuerdo al Informe del Banco Mundial (2003) existirían tres motivos generales de preocupación:

Primero, la existencia de mayores niveles de inequidad, ya sea en el ingreso u otras dimensiones de bienestar, lo que significa más pobreza en un momento determinado. Asimismo, supone que el desarrollo ejercerá un menor efecto dinámico sobre la pobreza, a menos que se realice una redistribución significativa.

Segundo, la desigualdad puede desacelerar el proceso general de desarrollo. La mayoría de los economistas (y otros cientistas sociales) consideran la desigualdad como un posible freno para el desarrollo, por diversos motivos: la desigualdad en el acceso al crédito significa perder oportunidades de inversión muy rentables para la economía en su conjunto; la desigualdad de oportunidades educacionales limita la posible contribución a la sociedad de algunos de los individuos más talentosos; los conflictos de distribución se acentúan, en especial, en el marco del manejo de shocks adversos; la delincuencia y la violencia aumentan; y en algunas condiciones, las bases institucionales para el crecimiento se debilitan, por ejemplo, con respecto a los derechos de propiedad.

En tercer lugar, el alto nivel de desigualdad es rechazado en forma generalizada en casi todos los países encuestados por Latinobarómetro ${ }^{4}$, el $80 \%$ y el $90 \%$ de los ciudadanos considera que las tasas de inequidad imperantes son injustas o muy injustas.

Paulette Dieterlen (En Ziccardi 2001: 14), reconoce que si bien existe en la mayoría de los países un interés en combatir la pobreza por su aspecto disfuncional, dado que los pobres constituirían un freno para el desarrollo económico de un país, es indispensable tomar en cuenta el aspecto ético del problema. Dado que desde este punto de vista, la pobreza es un mal en sí mismo. Quienes la padecen carecen de lo indispensable para ejercer el más mínimo grado de autonomía y de oportunidades para llevar a cabo ciertos planes de vida.

El estudio Latinobarómetro es producido por la Corporación Latinbarómetro. ONG sin fines de lucro. 
La desigualdad de oportunidades resulta particularmente inaceptable en términos éticos, lo cual significa que los individuos enfrentan opciones de vida totalmente diferentes al nacer, y es específicamente nociva para el potencial de crecimiento general de la sociedad.

Al aproximarnos a la realidad de América Latina desde las cifras, ${ }^{5}$ nos encontramos con que según diversos actores, la pobreza sería el primer problema de la región, el 39\% de la población están en esa condición (210 millones de habitantes, de los cuales 98 millones están en extrema pobreza. Bolivia y Honduras son los que están en peor condición. (Arroyo 2004)

Adela Cortina, en la ponencia central presentada en el $33^{\circ}$ Congreso Mundial de Escuelas de Trabajo Social, señala que la desigualdad en nuestras sociedades es la más grande del mundo. Plantea la autora que en América Latina "las desigualdades son las mayores de la tierra y la pobreza, extrema, a pesar de las grandes diferencias que existen entre unos países y otros" (Cortina 2006)

Igualmente, la CEPAL nos dice que durante los años ' 90 se ha mantenido o acentuado la alta concentración de la distribución del ingreso que caracteriza a la mayoría de países de la región.

Frente al tema de la desigualdad surge necesariamente el tema de la equidad, la que generalmente ha sido entendida como "tratar a cada uno según su necesidad" (Ethos № 23), también como aquella cualidad que consiste en dar a cada uno lo que se merece por sus méritos o condición. Squella (1998: 144) señala que por contraposición a lo justo legal, se ha considerado a la equidad como la justicia del caso particular.

En este contexto, la equidad se refiere al uso de recursos públicos para redistribuirlos con el propósito de dar satisfacción a necesidades humanas dispares. "Desde un punto de vista económico se la entiende como la obligación del Estado de proveer igualdad de oportunidades."(Nilo 2000)

Para más detalles ver: Arroyo, Pilar (2204) Análisis del Contexto Actual Latinoamericano. Primera Parte: Contexto Actual de América Latina. Documento circulación restringida Estudio de la realidad social latinoamericana encargado por la Congregación Trinitaria. Perú. 
Al respecto, Meller (1997) se hace la siguiente pregunta: ¿Por qué surge la preocupación social por la desigualdad? La respuesta es, simplemente, porque vivimos en sociedad. "El ser humano no vive aislado; existe interacción y dependencia mutua entre los individuos, y esto genera necesariamente responsabilidades mutuas" (Meller 1997:19) Se trata de una desigualdad entendida en sentido amplio, no sólo de distribución del ingreso, sino referida al ejercicio de derechos, libertades, capacidades, o a la estima y reconocimiento social.

Por su parte, Urzúa (1998) nos señala que no hay evidencia histórica de sociedades totalmente igualitarias, siendo la desigualdad una constante ya que "todas la desigualdades, son, en definitiva, desigualdades sociales construidas a partir de una u otra características individual, a la cual se le atribuye consecuencias socialmente definidas como positivas o negativas" (Urzúa 1998:138)

Es en esta realidad, de cara a las desigualdades, donde el Trabajo Social interviene y es allí donde nos volvemos a preguntar ¿cómo enfrentar este mundo donde se nos representan múltiples fragilidades y potencialidades?

\section{Síntesis}

Luego de este breve recorrido, diremos que hablar de igualdad, en el sentido estricto del término, en lo referido a igualdad de acceso a diversos medios para el logro de objetivos individuales, pareciera ser la definición conceptual que está en oposición al concepto de desigualdad. No obstante, desde los postulados de Amartya Sen surge una propuesta referida a la igualdad de capacidades "mirar el problema desde la perspectiva de las capacidades obliga a poner atención en como la estructura social está negando o favoreciendo la libertad fundamental de todas las personas para desarrollar sus capacidades" (En: Urzua, 1998:138) En tal sentido, ¿cuál es el tipo de sociedad que se requiere para que todos seamos igualmente libres para poder desarrollar nuestras capacidades?

Si ya sabemos que la desigual distribución de la riqueza / pobreza, vista no sólo desde el punto de vista económico, sino también desde la posibilidad de desarrollar las capacidades, es un componente que está presente en las sociedades latinoamericanas, permeando la cotidianidad de las vidas de las personas, es necesario, no sólo 
preguntarnos, sino también proponer acciones que permitan buscar salidas a la situación en que viven millares de personas en América Latina.

Es precisamente esa cotidianidad la que llegamos a conocer los trabajadores sociales, es en esta cotidianidad que se padece la pobreza, y donde es necesario generar propuestas que permitan abrir espacios a la intervención profesional.

Una dimensión de la intervención profesional que tenemos que considerar es la dimensión ética. Si concordamos en que el Trabajo Social es un saber complejo y fundado sobre lo social, en un contexto de cambios profundos; y que además el trabajo social, es un saber discernir en lo social los signos que apuntan hacia un desarrollo más humano y sustentable, o por el contrario, es saber detectar oportunamente aquellas situaciones y signos que nos deshumanizan. Entonces, hemos de aceptar que la ética es una dimensión constitutiva de la profesión y como tal, se relaciona con la comprensión que tenemos de lo social y con las orientaciones para la actuación profesional.

Al reconocer la desigualdad como un desafío que interpela la intervención del trabajador social surge, desde la ética, el desafío de resituar el valor de la justicia social en las circunstancias actuales, ésta se constituirá en una intencionalidad convocante de la actuación profesional en medio de las incertidumbres y riesgos de la vida cotidiana; en tanto valor ético y político que abre nuevas posibilidades para recrear el oficio profesional. De ser así, se abrirían posibilidades a un Trabajo Social, que en el contexto neoliberal y de globalización de las sociedades contemporáneas, busca reafirmar el espíritu crítico de sus orígenes, la transformación social y la solidaridad como expresión del respeto por la dignidad de cada persona humana, sobrepasando de esta forma los límites del sistema.

Desde el Trabajo Social, entendemos que la justicia se perfila como una idea dinámica, como una tarea que nunca termina y que ese anhelo de una sociedad más justa, ha sido, es y seguirá siendo necesario si queremos construir sobre una base sólida los procesos de transformación social y con ellos de la identidad profesional. 


\section{Bibliografía}

Arroyo, Pilar (2004) Análisis del Contexto Actual Latinoamericano. "Contexto actual de América Latina”. Documento circulación restringida.

Banks, Sara (1997) Ética y valores en el trabajo social. Editorial Paidos, Barcelona

Barros, Paula; De los Ríos, Danae Torche, Florencia (1996)

Lecturas sobre la Exclusión Social. OIT. Documento de Trabajo No 31. Santiago de Chile.

Cortina, Adela (2006) "Ética pública desde una perspectiva dialógica". Ponencia Central $33^{\circ}$ Congreso Mundial de Escuelas de Trabajo Social. Santiago de Chile.

Informe Ethos $\mathrm{N}^{0} 23$. s/a Elementos para el Discernimiento, párrafo 22.

Meller, Patricio (1997) El modelo económico y la cuestión social. Serie Estudios Socioeconómicos $\mathrm{N}^{\circ} 1$. Universidad de Chile, Chile

Mideplan (2002) Síntesis de los principales enfoques, métodos y estrategias para la superación de la pobreza. Gobierno de Chile. Santiago.

Netto, Paulo (2006) A ordem social contemporânea é o desafio central" Ponencia Central $33^{\circ}$ Congreso Mundial de Escuelas de Trabajo Social. Chile.

Nilo, Sergio (2000) "Análisis de investigaciones recientes sobre la incidencia del mercado en la calidad de la educación". Departamento de Educación, Facultad de Ciencias Sociales Universidad de Chile. Revista Enfoques Educacionales Vol. $2 \mathrm{~N}^{\circ} 2$. Santiago de Chile

Sánchez, Daniela (1984) Notas sobre Calidad de Vida y Trabajo Social. Revista Apuntes para Trabajo Social N 4-5, 1984

Silver (1994) En: Barros, Paula; de los Ríos Danae; Torche, Florencia. En: Exclusión social y políticas sociales: una mirada analítica. OIT.1996

Social Watch (2005) Informe 2005. Rugidos y Murmullos. Instituto del Tercer Mundo. Uruguay.

Squella, Agustín (1998) “¿Necesitamos desarrollo con equidad o con 
igualdad?" En: Ética, democracia y desarrollo humano. Cristián Parker (ed) LOM-CERC-UAHC. Santiago de Chile.

Urzúa, Raul (1998) "Cultura Cívica, desigualdad y equidad en Chile". En: Etica, democracia y desarrollo humano. Edición a cargo de Cristián Parker. LOM ediciones - CERC-UAHC.

Ziccardi, Alicia (2001) Pobreza, desigualdad social y ciudadanía. Los límites de las políticas sociales en América Latina. CLACSO Buenos Aires, Argentina.

\section{Recursos electrónicos}

Banco Mundial (2003) Informe Desigualdad en América Latina y el Caribe: ¿ruptura con la historia? En: http://www.fedesarrollo.org.co/eventos/la10022004/banco_mundial_resumen.pdf 